\title{
THE SPATIAL DISTRIBUTION CHARACTERISTICS OF ENTERPRISES IN BEIJING CHAOYANG CBD
}

\author{
Hanming $\mathrm{Gu}$ \\ SHU-UTS SILC Business School, Shanghai University, P.R.China \\ Yuegang Chen \\ SHU-UTS SILC Business School, Shanghai University, P.R.China
}

\begin{abstract}
Beijing Chaoyang CBD plays a pivotal role in Beijing becoming one of the economic operation and control centers in the Asia-Pacific region. By using SPSS analysis, spatial Gini coefficient, Kriging interpolation method and kernel density estimation, we analyze the spatial distribution characteristics of 2592 enterprises in 40 buildings in the area. We find that the spatial distribution of enterprises here is consistent with the "core-periphery" pattern. An industrial ecosystem with the leading industry of leasing and commercial industry as well as financial industry is formed. High influential enterprises also agglomerate densely in the area.
\end{abstract}

Keywords: Beijing Chaoyang CBD, spatial agglomeration, “core-periphery” pattern

JEL code: R1, R3

\section{Introduction}

The central business district (CBD) is a symbol of urban modernization. It is a place where many finance, business, culture and various service enterprises aggregate. Mostly, CBDs locate in the core areas of a country or city. As an international metropolis, Beijing also has a Chaoyang $\mathrm{CBD}$, which has played an important role in the development of the economy. Beijing Chaoyang CBD used to be a heavy industrial area. However, after decades of development, it has become a highly developed commercial area where a large number of outstanding domestic and foreign enterprises have agglomerated in it. How these enterprises agglomerate? What are the main industries? Why they choose to be here? These are some meaningful questions not only for the present research but also for the future development of Beijing Chaoyang CBD, even for the reference of Beijing-Tianjin-Hebei urban agglomeration development.

\section{Literature Review}

Spatial distribution has always been a hotspot in academia and politics home and abroad. 
Ellison and Glaeser (1999) find that the natural advantages have a great impact on industry agglomeration through investigation. Rosenthal and Strange (2001) use E-G coefficient to estimate the degree of manufacturing agglomeration in USA from three angles of the county, state and zip code. Wood and Parr (2005) regard that languages, systems, business and cultures differ in geographical space and they will affect the transaction cost in some degree. Combes et al. (2010) analyze the industry agglomeration with three independent factors, i.e. history, geography and labors. Carlsson (2013) studies the effect of the knowledge flow on agglomeration in high-tech industry via the propagation mechanism and the innovation mechanism. Vang and Jakobsen (2013) analyze the feasibility of establishing a film industry with similar aggregation degree in other regions by drawing on the successful Hollywood film industry. Brulhart and Simpson (2015) analyze the relationship between industry agglomeration and government policy through the government financial subsidies data of the relatively backward areas in UK. Lu and Tao (2007) use E-G coefficient as a measurement of industry aggregation degree to study the affecting factors of the manufacturing industry in China. Zhang (2012) use fixed effect model to prove that the economic effect, trade demand, government support, geographic location, etc. will have a positive influence on the financial industry agglomeration degree. Chang and Zhang (2015) analyze agglomeration characteristics and spatial pattern of the service industry in Beijing-Tianjin-Hebei metropolitan area with Herfindahl coefficient, spatial Gini coefficient and spatial auto correlation method.

Through the above literature review, our predecessors have studied spatial agglomeration from various aspects. Whereas, most previous studies are based on a relatively large geographical scale. Only a few studies are from the perspective of a particular area within the city. This paper reveals the spatial distribution characteristics of enterprises in Beijing Chaoyang CBD through proving three hypotheses by using different methods.

\section{Hypotheses and Methods}

\subsection{Hypotheses}

Beijing Chaoyang CBD begins on East Second Ring in the west and ends up on East Fourth Ring in the east, with Tonghui River on its south and Chaoyang North Road on its north. It is in a very convenient location where the highways, subways and airport surround or near it. What's more, many foreign embassies are distributed both inside and outside, providing great convenience for their domestic enterprises to invest and develop business services.

Beijing Chaoyang CBD used to be a small area. According to the history, we divided the area into three parts. The "Middle Area" begins on East Bridge Road in the west and ends up on West Dawang Road in the east, with Tonghui River on its south and Chaoyang North Road on its north. The left one is called the "West Area", and the right one is called the "East Area". We can see the whole view from figure 1. 


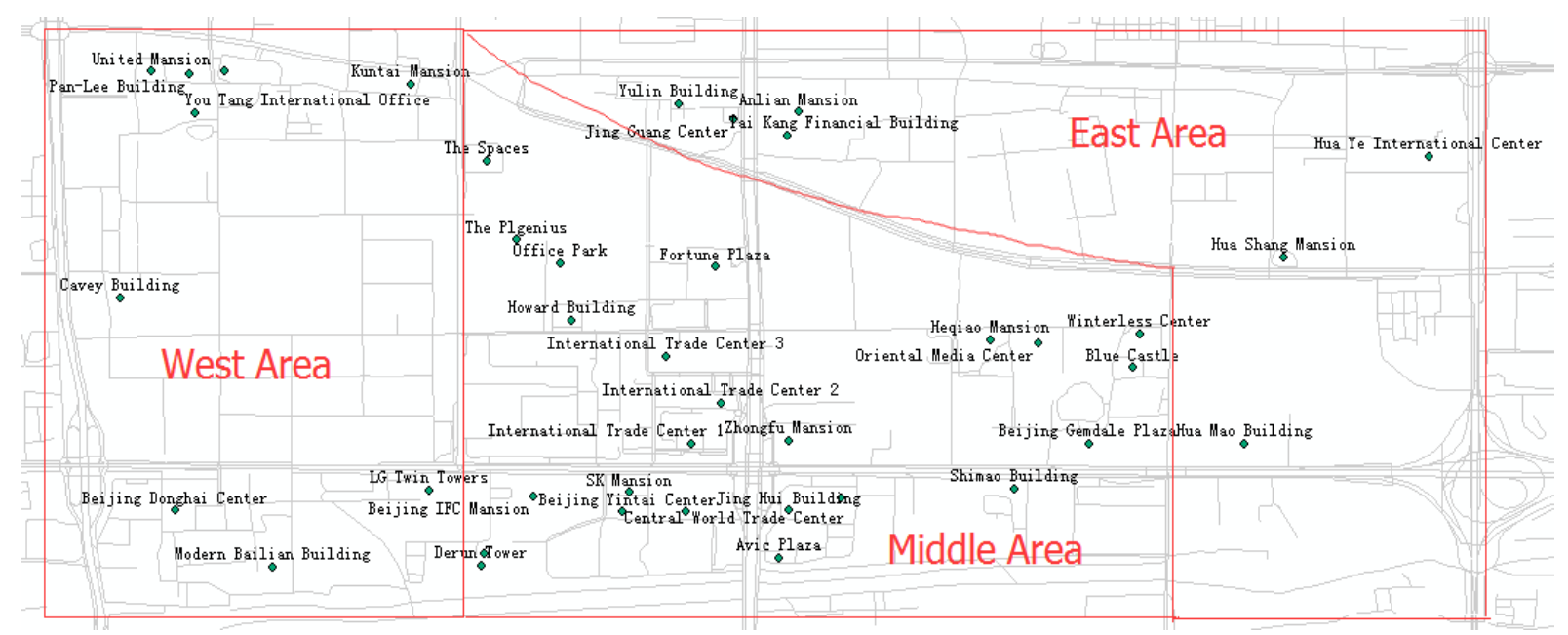

Figure 1. Whole view of Beijing Chaoyang CBD

After analyzing 2592 enterprises from 40 famous commercial buildings in Beijing Chaoyang CBD, which includes enterprises' names, addresses, main business, etc., and combining its history with current situation, we put forward three hypotheses:

H1: The spatial distribution of enterprises in Beijing Chaoyang CBD is consistent with the "core-periphery" pattern. The core part is the Middle Area and the periphery part is composed by the other two areas.

H2: There has formed an industrial ecosystem in Beijing Chaoyang CBD and the leading industry is the commercial services industry.

H3: The influential enterprises are only agglomerated mainly in the Middle Area of Beijing Chaoyang CBD.

\subsection{Methods}

We use some statistical analysis, spatial Gini coefficient, Kriging interpolation method and kernel density estimation to analyze the data.

Spatial Gini coefficient (SPC) evolves from Gini distribution coefficient, which is used to measure the uneven spatial distribution degree of enterprises. According to some relevant provisions of the United Nations, the spatial Gini coefficient are divided in Table 1.

Table 1. The division of the spatial Gini coefficient

\begin{tabular}{|l|l|l|}
\hline SPC & Spatial distribution & Aggregation \\
\hline Below 0.2 & Even & No aggregation \\
\hline $0.2 \sim 0.3$ & Relatively even & Little aggregation \\
\hline $0.3 \sim 0.4$ & Uneven & Aggregation \\
\hline $0.4 \sim 0.5$ & Relatively uneven & Obvious aggregation \\
\hline Above 0.5 & Extremely uneven & Very obvious aggregation \\
\hline
\end{tabular}


Kriging interpolation method, also known as spatial self-covariance optimal interpolation method. According to the method, sample points have spatial correlation based on distance or direction, then a smooth surface raster based on the measured value of the sample points generates, which can forecasts the values around sample points. We use this to see the agglomeration degree of each industry.

Kernel density estimation is applied to the study of point distribution, which is the probability that a single geographical event can occur at any position in space and occur at different locations. If a certain area is densely distributed, the probability of geographical events in the region is high, and vice versa. In this study, the spatial distribution characteristics of influential enterprises in 40 buildings are calculated with it.

\section{Results}

\subsection{Spatial Distribution Pattern}

We classify the 2592 enterprises in 40 buildings and find that in the Middle Area the number of buildings or enterprises are far more than the others. There are 26 commercial buildings and 1753 enterprises, accounting for $67.63 \%$ of the total number of enterprises. The West Area has 9 buildings and 537 enterprises, accounting for $20.72 \%$ of the total, while the East Area only has 5 buildings and 302 enterprises, accounting for $11.65 \%$ of the total (Figure 2).

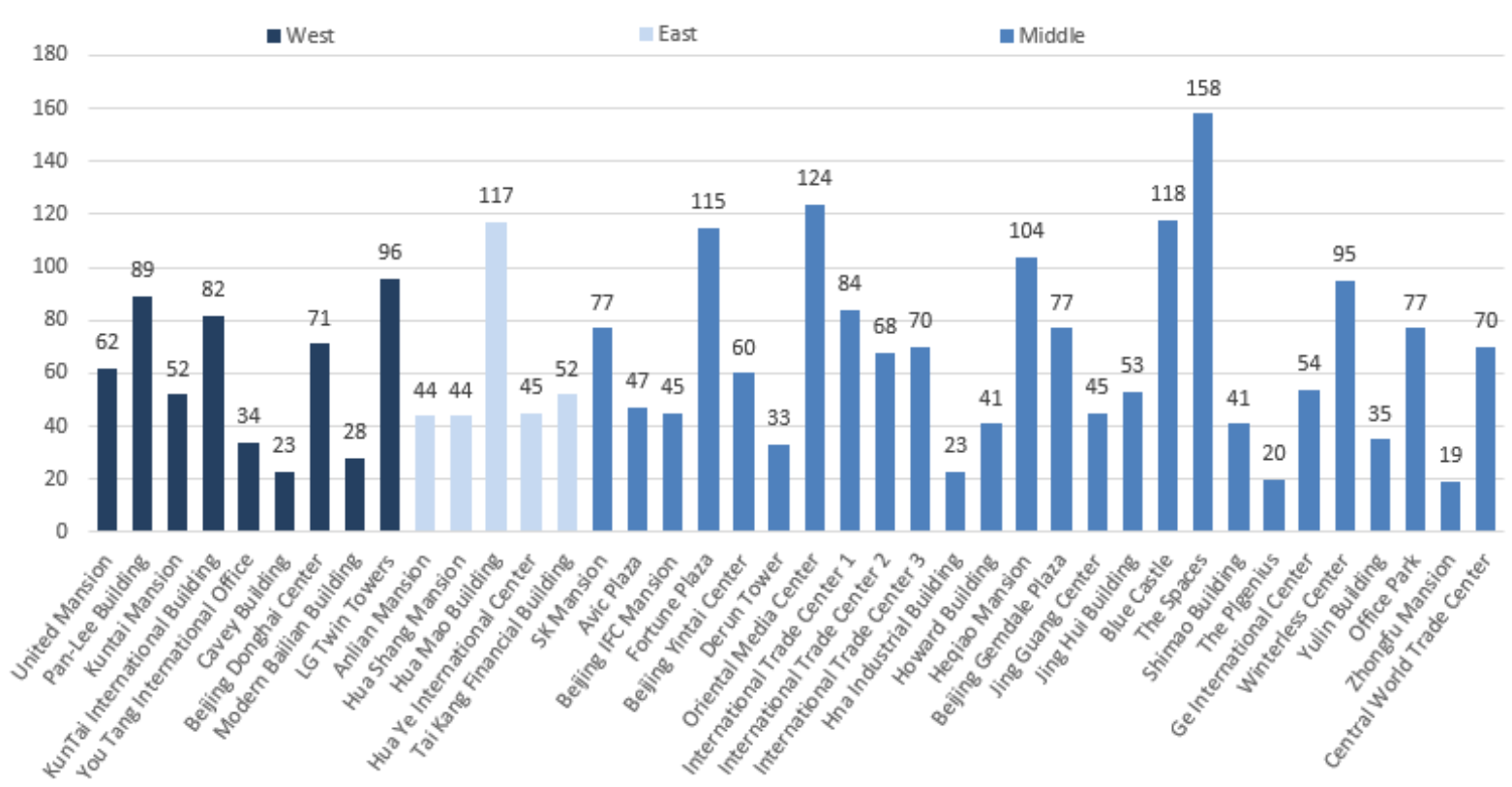

Figure 2. The distribution statistics of enterprises in three areas

From the above, we can see that the spatial distribution of enterprises in Beijing Chaoyang CBD is in line with the "core-periphery" pattern. The core area is the Middle Area, and the peripheral area is composed by the East and West Area. Therefore, H1 is true. 


\subsection{Industrial Ecosystem}

According to the "National Economy Industry Classification Standard" (GB/T4759-2011) and the main business of enterprises, we divide them into 13 categories of industry. However, some industries has so few enterprises, so we screen the data and leave 8 main categories of industry, which are as follows: leasing and commercial services industry (L, 31.71\%, 799), financial industry (J, 26.51\%, 668), manufacturing industry (C, 13.41\%, 338), wholesale and retail trade industry (F, 11.07\%, 279), software and information technology services industry (I, 9.84\%, 248), real estate industry (K, 3.57\%, 90), transportation, warehousing and postal service industry $(\mathrm{G}, 2.3 \%, 58)$, construction industry (E, 1.59\%, 40), a total number of 2520 enterprises (Figure 3).

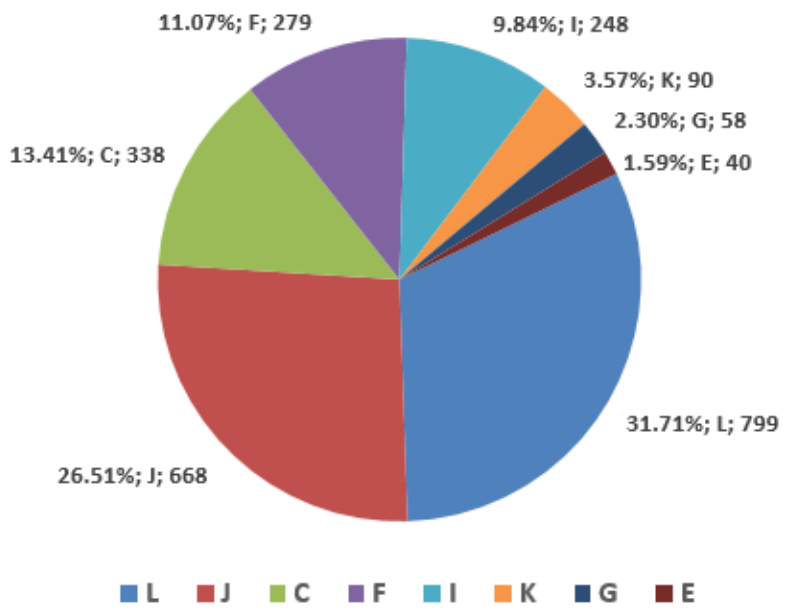

Figure.3 The enterprises’ distribution statistics of eight industries

Then we calculate the spatial Gini coefficients of the eight industries in this part. The result is shown in Table 2.

Table. 2 The spatial Gini coefficients of the eight industries in 40 buildings

\begin{tabular}{|l|l|l|}
\hline Industry name & Code & Gini \\
\hline Manufacturing & C & 0.346 \\
\hline Construction & E & 0.611 \\
\hline Wholesale and retail trade & F & 0.367 \\
\hline Transportation, warehousing and postal service & G & 0.473 \\
\hline Software and information technology services & I & 0.414 \\
\hline Financial & J & 0.391 \\
\hline Real estate & K & 0.314 \\
\hline Leasing and commercial services & L & 0.340 \\
\hline
\end{tabular}

The spatial Gini coefficients are all above 0.3, which means the spatial aggregation exists in all the industries. Manufacturing industry, wholesale and retail trade industry, financial industry, real estate industry, and leasing and commercial services industry are in range 
$0.3 \sim 0.4$, indicating that there is aggregation. Transportation, warehousing and postal service industry as well as software and information technology services industry are in the range of $0.4 \sim 0.5$, indicating that there is obvious aggregation. Construction industry is above 0.5 , indicating that there is very obvious aggregation.

For a better view of the agglomeration degree of the eight industries, we use Kriging interpolation method to draw the density interpolation maps, which are listed below (Figure 4 to Figure11). The deeper the color is, the higher degree of agglomeration it represents. Figure 12 shows the aggregation degree standard.

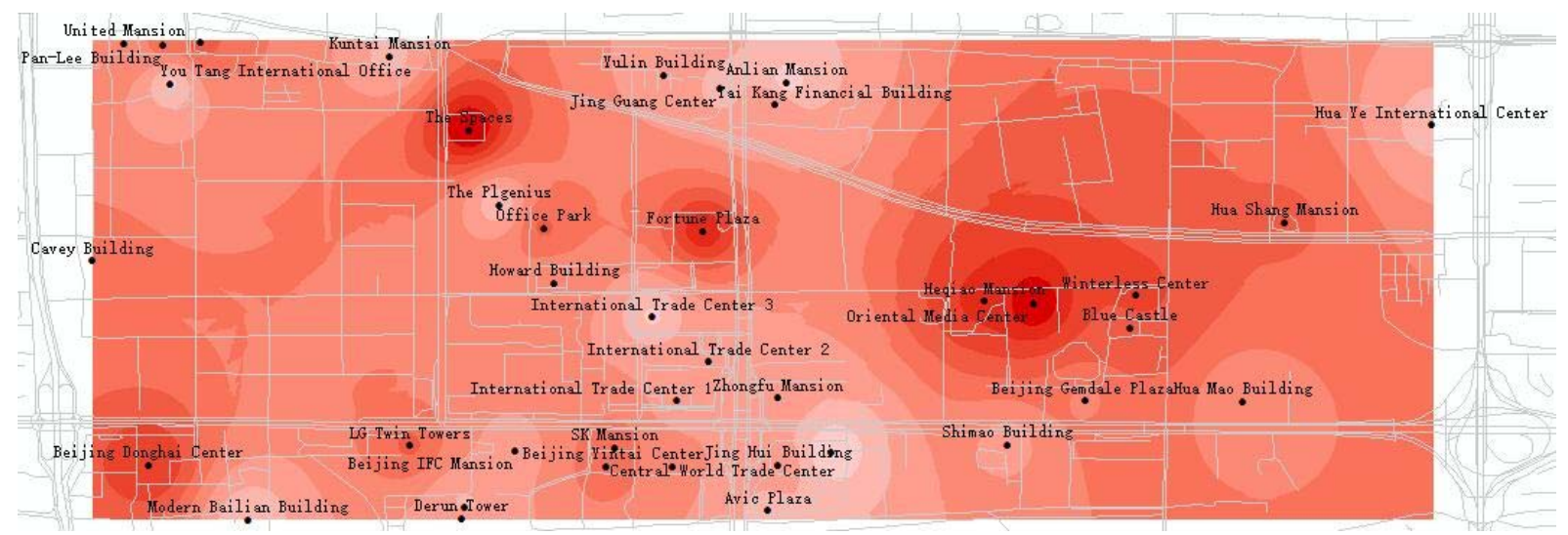

Figure.4 The distribution density of manufacturing industry

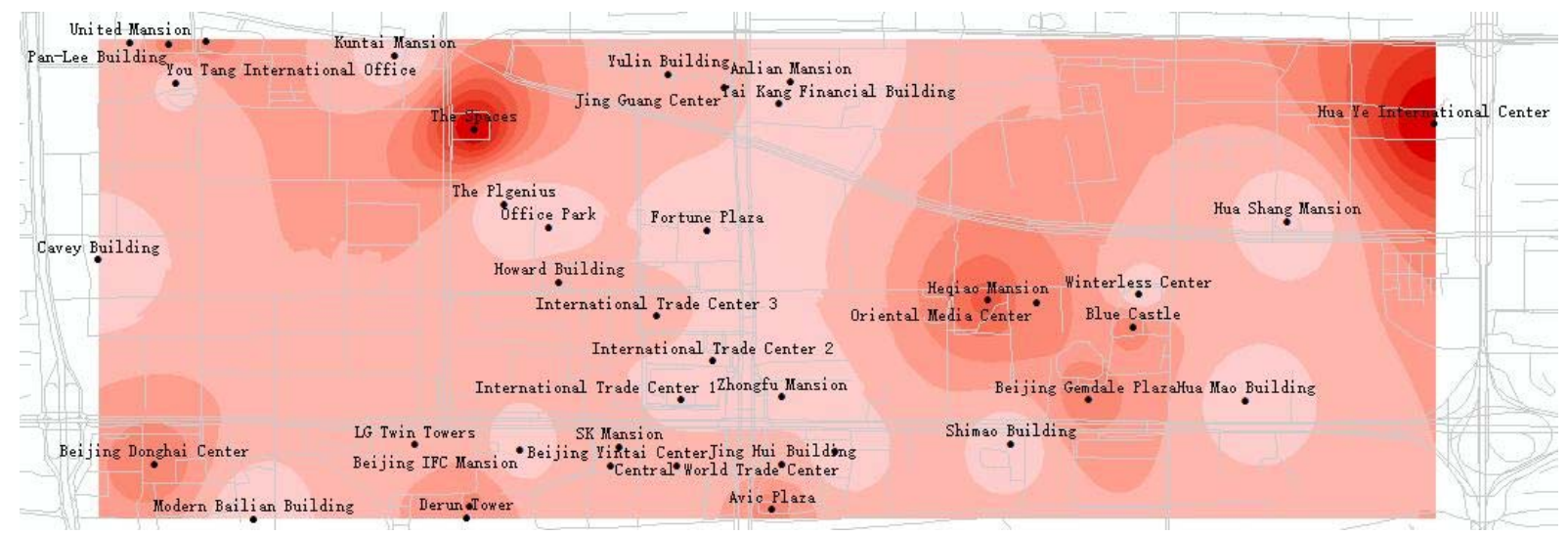

Figure.5 The distribution density of construction industry

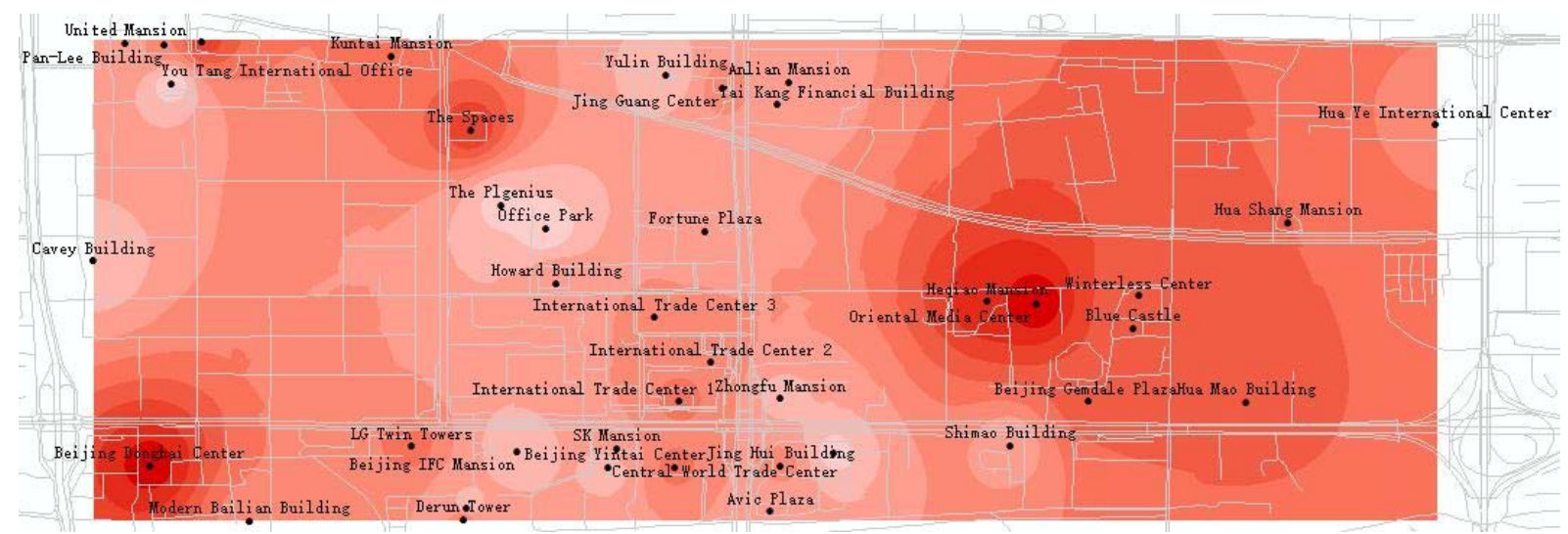

Figure.6 The distribution density of wholesale and retail trade industry 


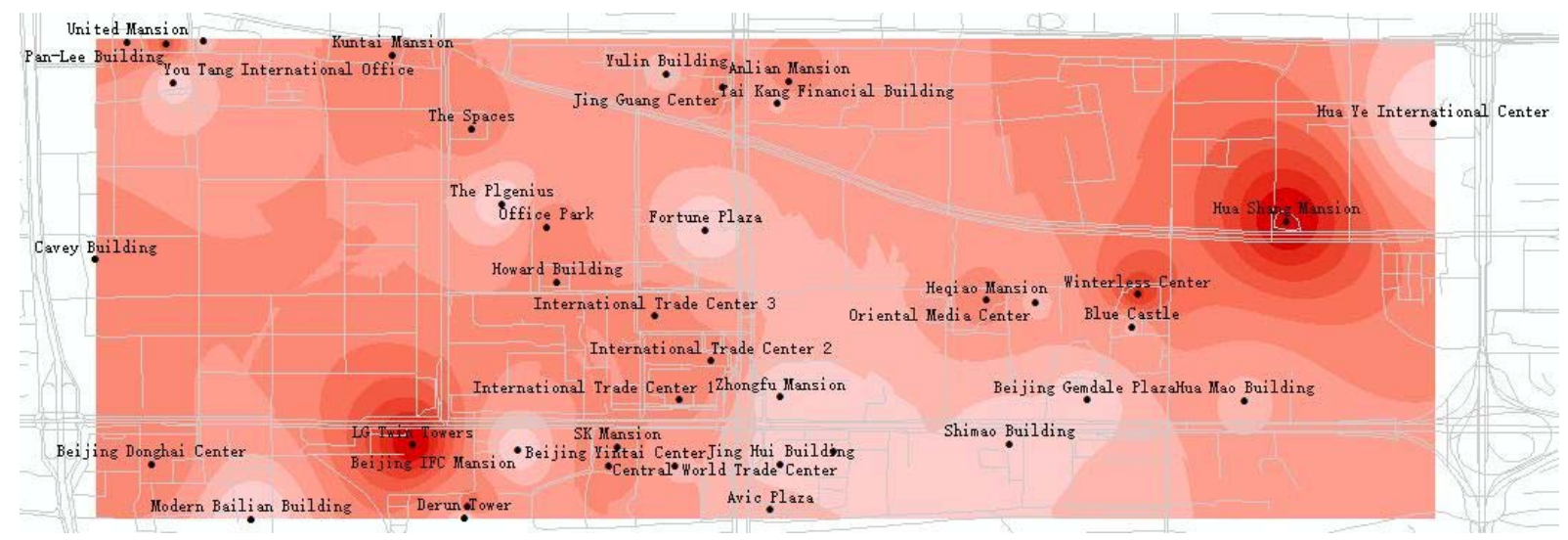

Figure.7 The distribution density of transportation, warehousing and postal service industry

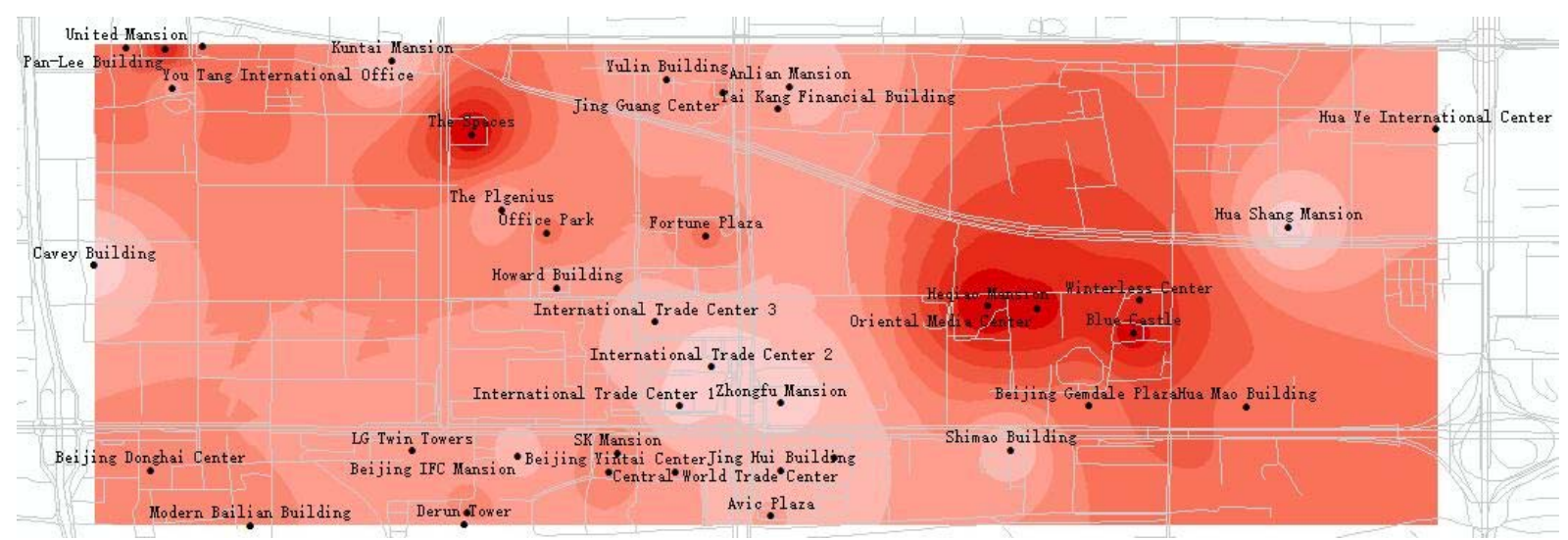

Figure.8 The distribution density of software and information technology services industry

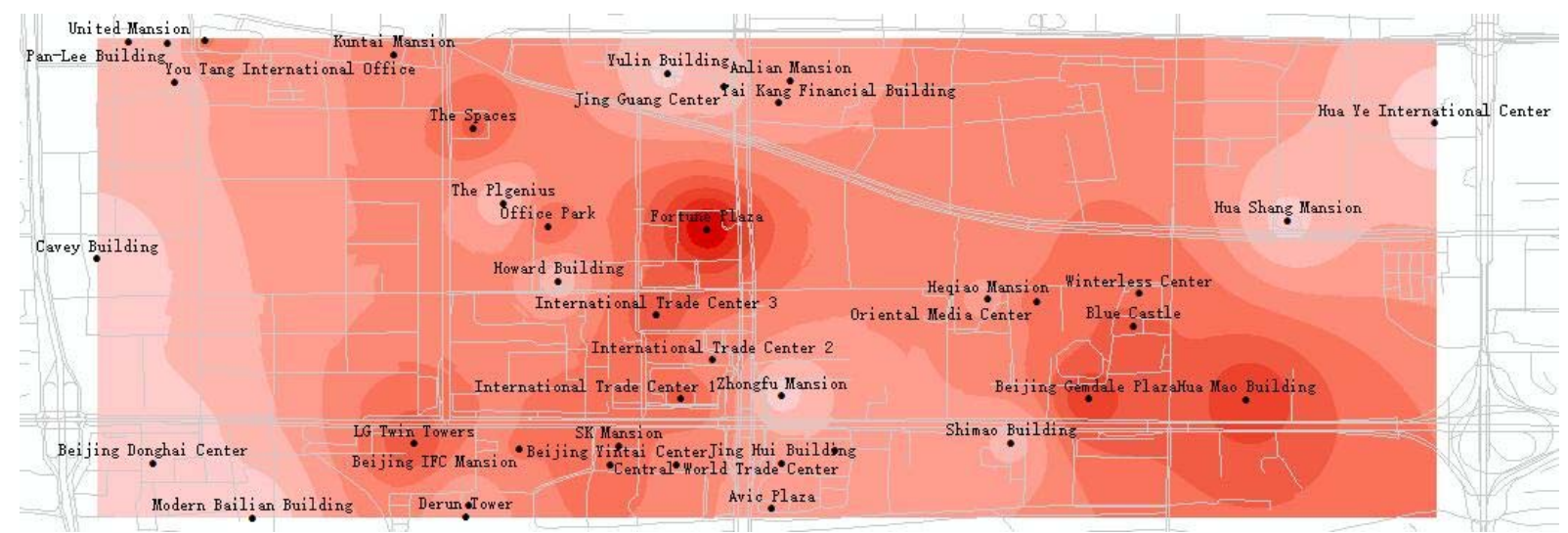

Figure.9 The distribution density of financial industry 


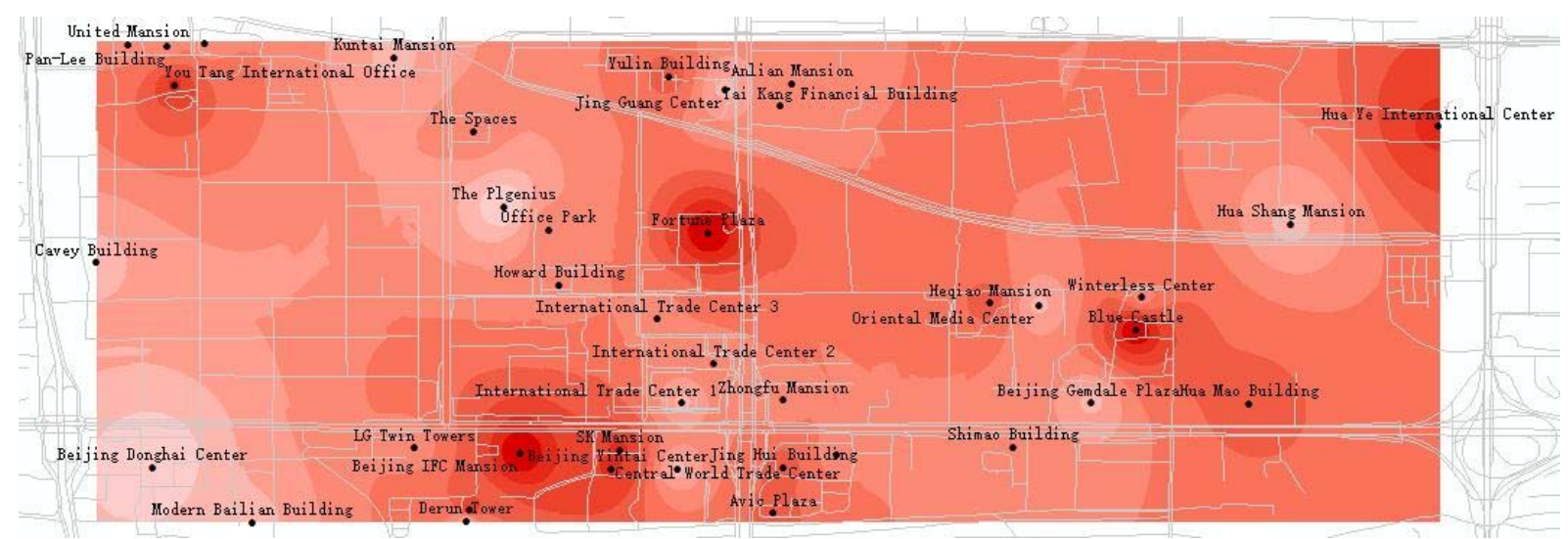

Figure.10 The distribution density of real estate industry

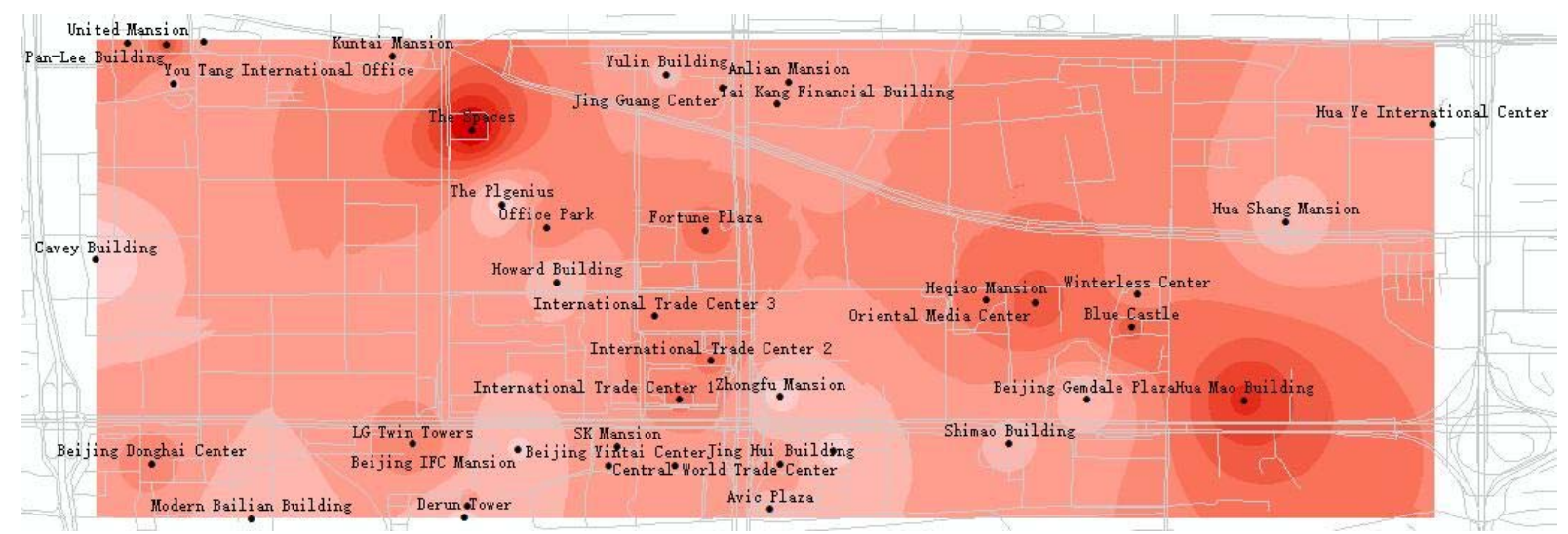

Figure.11 The distribution density of leasing and commercial services industry
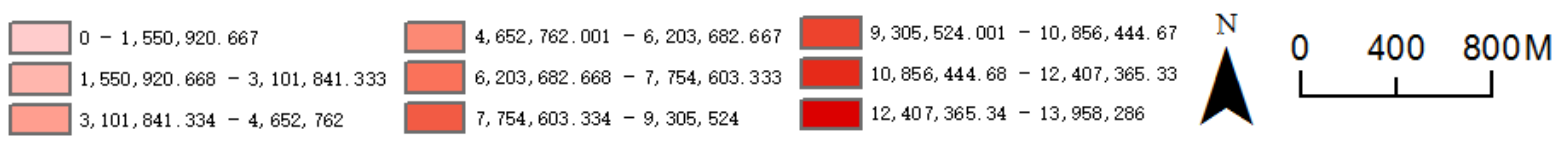

Figure.12 The aggregation degree standard from low to high

Through the above analyses, H2 is partly true. All industries agglomerate in the core part. Some industries mainly agglomerate in the periphery part, but their agglomeration location is very close to the boundary of core part and the periphery part. The leasing and commercial services industry and financial industry outnumber other industries, whereas their agglomeration degrees are not very high. In general, finance, insurance, securities, mediation and other modern service industry as representatives of the third industry have become the dominant industry in Beijing. Their development also result in its upstream and downstream enterprises gathering around them, and the whole area forms a relatively complete industrial ecosystem.

\subsection{Spatial Distribution of Influential Enterprises}

Influential enterprises are those who possess a lot of resources and a good popularity, which can promote regional economy and competiveness to a large scale. Considering scale, revenue, popularity and other considerations, we define influential enterprises as follows: (1)listed companies; (2)large state-owned enterprises; (3)World or China top 500; (4)banks, 
brokerages, funds; (5)large consulting firms, accounting firms, law firms and media organizations;(6)insurance companies; (7)other influential institutions. According to the above criteria, we select 1023 influential enterprises out of the total 2592 enterprises. The distribution of the influential enterprises in 40 buildings is shown below:

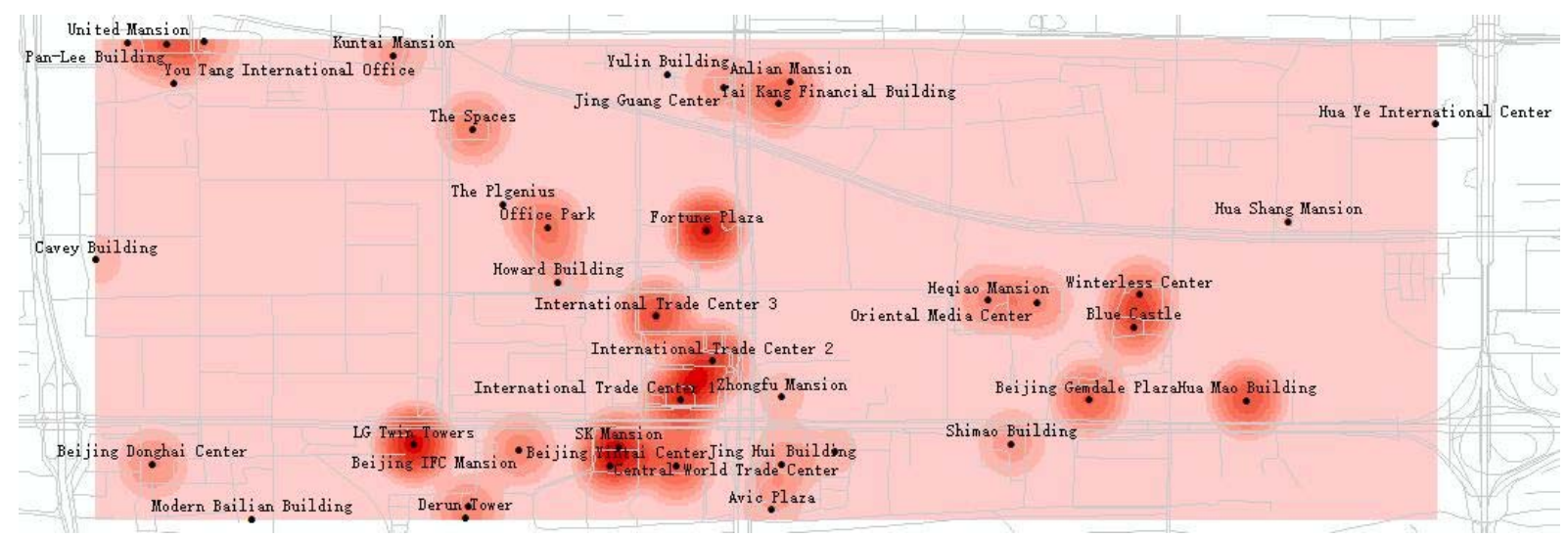

Figure.13 The kernel density distribution of the influential enterprises

In Beijing Chaoyang CBD, there are 737 influential enterprises in the Middle Area, accounting for $72.04 \%$ of the total influential ones. While there are only 176 in the West Area and 110 in the East Area, accounting for $17.21 \%$ and $10.75 \%$ respectively. The influential enterprises are mainly agglomerate in the core part. In the West Area, only LG Twin Towers is the highland of agglomeration. In the East Area, only Hua Mao Building is the highland of agglomeration. Therefore, hypothesis 3 is proven to be true.

\section{Affecting Factors of These Spatial Distribution Phenomena}

By proving the above three hypotheses, we find that the spatial distribution of enterprises here is consistent with the "core-periphery" pattern. An industrial ecosystem with the leading industry of leasing and commercial industry as well as financial industry is formed. High influential enterprises also agglomerate densely in the area. There are so many factors behind these phenomena, which can be classified as follows: history of contingent incidents; government planning and policies; economic externality; circulatory accumulation effect.

\subsection{History of Contingent Incidents Determine the Current Situation}

Beijing Chaoyang District is the largest, most populated and most prosperous area in Beijing. It used to be a heavy industrial area, which led the economy in 1950s in China. That formed its economy foundation. In 1980s, Chaoyang District was the first place to introduce foreign-funded companies. The construction of International Trade Center officially stood for the new era of international operation of foreign offices in eastern Beijing. In 1990s, with the continuous improvement of city modernization degree and international business activities, it was urgent for Beijing to have a central business district, which can provide all the aspects of infrastructure, convenient transportation and high quality business service. The government take that into the "tenth five-year plan". After a carefully and thorough investigation, the 
government finally decide to construct the central business district in Chaoyang District and officially named it as Beijing Chaoyang CBD. These historian incidents all together have formed the current situation of Beijing Chaoyang CBD.

\subsection{Government Planning and Policies Decide the Spatial Distribution of Enterprises}

Domestic and international experience shows that governments play a significant role in site picking and agglomeration evolution of enterprises. Generally, governments mainly provide regional planning guidance and policy guidance. One is about strategic guidance together with urban spatial planning, and the other is about lots of policies including talents, land, taxation, investment, etc. Since 1980s, Beijing government had invited many specialists to discuss about the CBD. It then issue a series of polices, such as "overall plan of Beijing urban construction”, "Beijing central area control detailed planning”, "outline of the tenth five-year plan for national economic and social development in Beijing”, "Revision of Beijing General Urban Planning” and so on. The government planned to build a CBD in Chaoyang District and made it as an important window for international communication. In order to encourage more multinational companies from overseas to set up their headquarters in Beijing, the government issued many preferential industrial policies including rebates, tax cuts, free land use of development zones for three years. Through strategic planning and combination of various policies, the number of multinational companies in Beijing is continuously increasing. With its superior geographical location and first-class investment environment, Beijing Chaoyang CBD has become a strong economic zone in Beijing.

\subsection{Economic Externality Has a Positive Effect on Industry Agglomeration}

Marshall believed that labor market, local market supply, transportation and other business related factors would have a great impact on the development of enterprises. If most of them are positive, they will generate benefits like information, technology, resources or cost reduction, resulting in industry aggregation (see Marshall, 2005). The government want to build Beijing Chaoyang CBD as a combination of modern service industry and high-end business district. Therefore, high-end services enterprises like finance, insurance, media, consulting companies mainly gather in the core area. However, other upstream or downstream enterprises such as manufacturing, retail and logistics ones are relatively agglomerate at the boundary where the core area connect the east and West Area. These industries all enjoy economic externality, the only difference is that the high-end services industries enjoy more than other ones. All in all, a good industrial ecosystem has formed and the economic agglomeration externality has already emerged in Beijing Chaoyang CBD.

\subsection{Cumulative Effect of Circulation can Strengthen the Stronger}

Myrdal believed there was a causal relationship among different socioeconomic factors in a dynamic social process. Once a particular socioeconomic factor changed, it would lead to another one, and the latter change in turn strengthened the previous one. This process formed a cumulative cycle of development trend (see Fujita, 2007). The original Beijing Chaoyang 
CBD was not as it is nowadays. It was only the Middle Area. It got the initial advantage to develop before other two areas. After decades of development, in 2009, the government expand it to the current size. It will take more time for the new areas to reach the prosperous state of the Middle Area according to the cumulative effect of circulation, because enterprises, especially business ones tend to agglomerate in the mature developed area to enjoy economic externality. That's why the Middle Area has become the core part, and so many influential enterprises and high-end services industries mainly aggregate in it.

\section{Conclusions}

In this study, we try to explore the spatial distribution characteristics of enterprises in Beijing Chaoyang CBD. Based on the above analyses, we come into the following conclusions:

Firstly, the spatial distribution characteristics of enterprises in Beijing Chaoyang CBD presents a "core-periphery" pattern. The Middle Area is the core part, while the West and East Area are the periphery part.

Second, the whole area has formed a relatively complete modern service industrial ecosystem with two leading industries of leasing and commercial services industry and financial industry.

Lastly, the Middle Area of Beijing chaoyang CBD is where the influential enterprises densely agglomerate. In contrast, there is very low aggregation degree of influential enterprises in the West and East Areas.

\subsection{Applied Implications}

The research studies the spatial distribution characteristics of enterprises in Beijing Chaoyang CBD. The findings has demonstrate the whole view of the current situation and there are still lots of difficulty we need to conquer. The core part is well developed, but the periphery part seems not to be good. Third industry distributes evenly in Beijing chaoyang CBD, but it's hard to tell the prominent characteristics of Beijing chaoyang CBD. And most influential companies tend to agglomerate in the core part. We find these phenomena hoping to better reveal the current situation to the government to make better decisions in future.

\subsection{Future Research Directions}

This article highlights the need for further analysis of the current situation from different directions. The results of the study only show a few aspects of Beijing Chaoyang CBD. There are other aspects we may study in the future research, such as talents, annually revenue, environment, real estates and so on. It should also be of interest to researchers studying the regional spatial distribution in other places, we hope more and more researchers will join us. 


\section{Acknowledgements:}

This research is financially supported by National Social Science Foundation (No. 13BGL154) and Humanities and Social Sciences of Ministry of Education Planning Fund (No. 12YJA790013).

\section{Reference}

Brulhart, M. and Simpson, H. (2015), "Agglomeration economies, taxable rents and government capture: evidence from a place-based policy", Journal of Economic Geography.

Carlsson, B. (2013), "Knowledge flows in high-tech industry clusters: Dissemination mechanisms and innovation regimes", Long Term Economic Development. Springer, pp. 191-221.

Chang, Y. and Zhang, L. (2015) "Features and spatial pattern of service industry agglomeration in Jing-Jin-Ji Metropolitan area", Urban Development Studies, vol. 22, pp. 59-65

Combes, P., Duranton, G., Gobillon, L. and Roux, S. (2010), "Estimating agglomeration economies with history, geology, and worker effects", Agglomeration Economics. University of Chicago Press, pp. 15-66.

Ellison, G. and Glaeser, E. L. (1999), "The geographic concentration of industry: does natural advantage explain agglomeration?”, The American Economic Review, vol. 89, no. 2, pp. 311-316.

Fujita, N. (2007), "Myrdal's Theory of Cumulative Causation", Evolutionary and Institutional Economics Review, vol. 3, no. 2, pp. 275-283.

Lu, J. and Tao, Z. (2007), "Study on the regional agglomeration level determinants of manufacturing industry in China", Quarterly Journal of Economics, vol. 04, pp. 801-816.

Marshell. (2005), "The Principle of Economics", Translated by Yunjie Lian. Beijing: Huaxia Pres.

Rosenthal, S. S. and Strange, W. C. (2001), "The determinants of agglomeration", Journal of Urban Economics, vol. 50, no. 2, pp. 191-229.

Vang, J. and Jakobsen, H. (2013), "The state and creative clusters: lessons on building a film cluster from scratch", International Journal of Business and Globalisation, vol. 11, no. 3, pp. 310-332.

Wood, G. A. and Parr, J. B. (2005), "Transaction costs, agglomeration economies, and 
industrial location", Growth and Change, vol. 36, no. 1, pp. 1-15.

Zhang, X. (2012), "Empirical analysis on the affecting factors of financial industry agglomeration", Journal of Nanjing University of Finances and Economics, vol. 01, pp. 59-64 